\title{
Patients with unbalanced atrioventricular canal defects can undergo the Fontan operation with good outcomes
}

\author{
Sitaram M. Emani, MD
}

\author{
From the Department of Cardiovascular Surgery, Boston Children's Hospital, Boston, Mass. \\ Disclosures: Author has nothing to disclose with regard to commercial support. \\ Received for publication Oct 27, 2016; accepted for publication Oct 27, 2016. \\ Address for reprints: Sitaram M. Emani, MD, 300 Longwood Ave, Bader 273, Boston, MA 02115 (E-mail \\ Sitaram.emani@cardio.chboston.org). \\ J Thorac Cardiovasc Surg 2017;153:439-40 \\ 0022-5223/\$36.00 \\ Copyright (c) 2016 by The American Association for Thoracic Surgery \\ http://dx.doi.org/10.1016/j.jtcvs.2016.10.061
}

The article in this issue of the Journal by Buratto and colleagues ${ }^{1}$ describes a single-institution experience with patients with a diagnosis of unbalanced atrioventricular septal defect who have undergone single-ventricle palliation. They report a sobering long-term survival in this patient population of approximately $60 \%$ at 15 and 25 years of follow-up after initial palliation. Patients who were able to undergo the Fontan procedure generally fared well, however, with high freedom from death or transplantation at long term.

The article of Buratto and colleagues ${ }^{1}$ highlights the progress that has been made with survival after the Fontan procedure. Timing of the Fontan procedure, specifics of surgical technique, better medical management and follow-up, and patient selection may factor into the excellent Fontan results seen in this study. Timing of the Fontan operation may affect the short- and long-term outcomes by several mechanisms. The median age at the Fontan procedure in this series was 5.8 years. Older age at operation may allow pulmonary vascular resistance to drop significantly enough to lower Fontan pressures and allow implantation of adequate-sized extracardiac conduit and less dependence on fenestration early after surgery. ${ }^{2}$ In other words, delaying the Fontan operation allows selection of patients who are be better candidates for singleventricle palliation. But delaying the operation also means that patients may die waiting for surgery, and thus selecting patients for the Fontan procedure in this manner shifts the risk to the interstage period. Patients with risk factors for the Fontan procedure, such as atrioventricular valvular regurgitation or pulmonary artery or vein stenosis, are likely to fall into this group of interstage mortality. This may explain the finding in the study that risk of having an intervention on the atrioventricular valve was lower in patients who underwent a Fontan completion than in those who did not. At Boston Children's Hospital, we prefer to perform the Fontan operation between 2 and 3 years of age, and this has a ripple effect in terms of operative management and outcomes. The strategy is typically

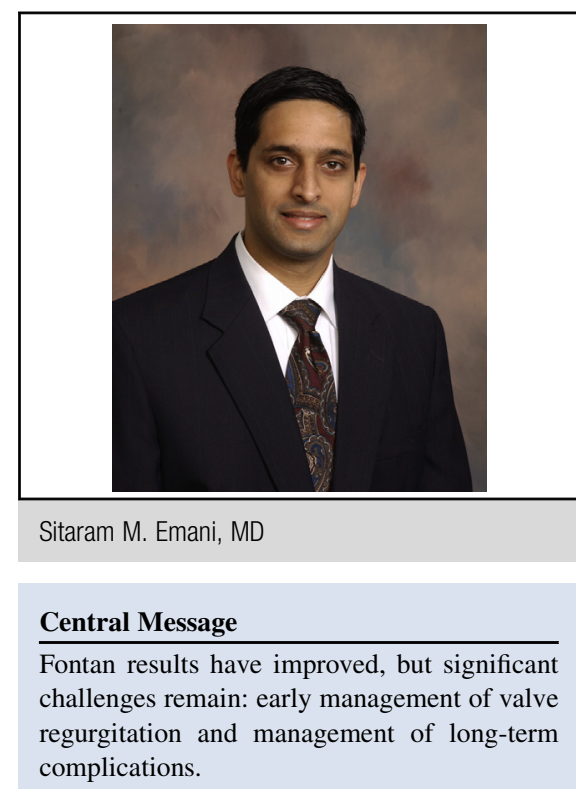

See Article page 430 .

chosen to avoid prolonged duration of cyanosis and to limit interstage mortality; however, this decision results in most patients undergoing a lateral tunnel Fontan procedure rather than an extracardiac conduit procedure. It also means that fenestration is often necessary at the original operation to avoid postoperative complications. This strategy may result in higher early and late mortality by shifting mortality of high-risk patients after the Fontan operation.

Buratto and colleagues ${ }^{1}$ also outline many of the challenges that we face with this patient population. First, morbidity of the Fontan circulation, including proteinlosing enteropathy, thromboembolism, arrhythmias, and plastic bronchitis, can be difficult to predict and treat. A second challenge is getting high-risk patients to survive to undergo the Fontan procedure. The significant mortality in this population occurred before the Fontan operation. The presence of atrioventricular valve regurgitation increases the risk of death after stages 1 and 2, and repairs performed at any stage are frequently not durable. The atrioventricular valves in this population, particularly in patients with heterotaxy syndrome, are notoriously difficult to repair. The mechanism of regurgitation is variable, and cleft closure or simple annuloplasty is insufficient 
to address leaflet prolapse and thickening frequently encountered.

Indeed, improvements in perioperative management and more judicious follow-up have improved the long-term outcomes of the Fontan operation, even in patients with unbalanced atrioventricular canal defect. ${ }^{3}$ Yet we still have room for significant improvement-in the management of patients with risk factors and in the management of complications when they occur.

\section{References}

1. Buratto E, Ye XT, King G, Shi WY, Weintraub RG, d'Udekem Y, et al. Long-term outcomes of single-ventricle palliation for unbalanced atrioventricular septal defects: Fontan survivors do better than previously thought. J Thorac Cardiovasc Surg. 2017;153:430-8.

2. Salazar JD, Zafar F, Siddiqui K, Coleman RD, Morales DL, Heinle JS, et al. Fenestration during Fontan palliation: now the exception instead of the rule. J Thorac Cardiovasc Surg. 2010;140:129-36.

3. Schumacher KR, Singh TP, Kuebler J, Aprile K, O'Brien M, Blume ED. Risk factors and outcome of Fontan-associated plastic bronchitis: a case-control study. J Am Heart Assoc. 2014;3:e000865. 